\title{
COMPARATIVE STUDY BETWEEN THIOPENTAL AND LIDOCAINE FOR PREVENTION OF PAIN ASSOCIATED WITH PROPOFOL INJECTION
}

\author{
Ajay Kumar1, Rashmi Taneja2, Nirupma Bansal3, Megha Soni4, Parul Gohil5, Gunjan ${ }^{6}$ \\ ${ }_{1}^{1}$ Assistant Professor, Department of Anaesthesia, ESIC Medical College, Faridabad. \\ ${ }^{2}$ Assistant Professor, Department of Anaesthesia, ESIC Medical College, Faridabad. \\ ${ }^{3}$ Associate Professor, Department of Anaesthesia, ESIC Medical College, Faridabad. \\ ${ }^{4}$ Senior Resident, Department of Anaesthesia, ESIC Medical College, Faridabad. \\ ${ }^{5}$ Senior Resident, Department of Anaesthesia, ESIC Medical College, Faridabad. \\ ${ }^{6}$ Senior Resident, Department of Anaesthesia, ESIC Medical College, Faridabad.
}

\begin{tabular}{l}
\hline ABSTRACT \\
BACKGROUND \\
Propofol causes pain or discomfort on injection in $28-90 \%$ of patients. This study was conducted to evaluate the efficacy of small \\
dose of thiopental $(0.5 \mathrm{mg} / \mathrm{kg})$ for prevention of pain associated with propofol injection and compare its efficacy with that of $2 \%$ \\
lidocaine $(40 \mathrm{mg})$ after manual venous occlusion at the forearm $1 \mathrm{~min}$. before injection of propofol.
\end{tabular}

\section{MATERIALS AND METHODS}

Double blind randomised study was conducted on hundred and fifty adult female ASA physical status I and II patients undergoing short gynaecological procedures. Patients were randomly assigned into three groups of 50 each. Group N received $2 \mathrm{~mL}$ of $0.9 \%$ saline, Group L received $2 \%$ lignocaine $(40 \mathrm{mg}$ ) and Group T received thiopental $0.5 \mathrm{mg} / \mathrm{kg}$. Pain was graded using four-point scale as $0=$ no pain, $1=$ mild pain, $2=$ moderate pain, $3=$ severe pain. The results were analysed statistically using unpaired student $t$-test and chi-square test.

\section{RESULTS}

The incidence of pain associated with propofol injection in saline group was $72 \%(36 / 50)$ as compared to $20 \%$ (10/50) in lidocaine group and 24\% (12/50) in thiopentone group. Pretreatment with thiopental was as effective as lidocaine to attenuate propofol injection pain when compared to saline group $(\mathrm{P}<0.05)$.

\section{CONCLUSION}

Thiopental pretreatment in dose range of $0.5 \mathrm{mg} / \mathrm{kg}$ along with manual venous occlusion for one minute is equally better alternative to Lidocaine with similar advantages.

\section{KEYWORDS}

Propofol, Thiopental, Lidocaine, Pain, Injection.

HOW TO CITE THIS ARTICLE: Kumar A, Taneja R, Bansal N, et al. Comparative study between thiopental and lidocaine for prevention of pain associated with propofol injection. J. Evolution Med. Dent. Sci. 2017;6(2):71-73, DOI: 10.14260/Jemds/2017/18

\section{BACKGROUND}

Propofol has become the intravenous drug of choice for many forms of anaesthesia, especially when rapid and complete awakening is desired. Indeed, awakening is more rapid and complete with propofol than with all other drugs used for induction of anaesthesia. Among 33 clinical problems, propofol-induced pain ranked seventh when both clinical importance and frequency were considered.(1) Propofol causes pain or discomfort on injection in $28-90 \%$ of patients.(2) Many methods such as addition of lignocaine to propofol, cooling or warming propofol, diluting the propofol solution, injection of propofol into a large vein and pretreatment with IV injection of ondansetron,

Financial or Other, Competing Interest: None.

Submission 29-11-2016, Peer Review 22-12-2016,

Acceptance 29-12-2016, Published 05-01-2017.

Corresponding Author:

Dr. Ajay Kumar,

B-4, 3067, Ridge View Apartment

Vasant Kunj,

New Delhi.

E-mail: ajayk17@gmail.com

DOI: $10.14260 /$ jemds $/ 2017 / 18$

\section{(c) $(i) \Theta$}

metoclopramide, an opioid or magnesium with or without tourniquet; all have been tried with variable results to reduce the incidence of pain on propofol injection.(3-9)

Nowadays propofol has become the intravenous induction of choice for almost all short duration surgical procedures, it is very much necessary to find out the most suitable analgesic agent for attenuating pain associated with propofol injection. This will help in reducing the morbidity associated with propofol injection and hospital discharge of patients with relatively pleasant memories. Pretreatment with thiopental in various doses has been used in different studies to attenuate pain during propofol injection. This study was conducted to evaluate the efficacy of small dose of thiopental $(0.5 \mathrm{mg} / \mathrm{kg})$ for prevention of pain associated with propofol injection and compare its efficacy with that of $2 \%$ lidocaine (40 $\mathrm{mg}$ ) after manual venous occlusion at the forearm $1 \mathrm{~min}$. before injection of propofol. Smaller doses of thiopental $(0.5 \mathrm{mg} / \mathrm{kg})$ were used to eliminate its sedative effect which can alter the perception of pain.

\section{MATERIALS AND METHODS}

After approval from institutional ethics committee and after obtaining written informed consent from patients, this prospective double blind randomised study was carried out 
on 150 adult female patients in age group of $18-50$ years undergoing short gynaecological procedures. Patients having communication problems, ASA grade III \& IV, history of allergies, hypersensitivity to barbiturates and lipids were excluded from the study. The patients were randomised according to a computer generated table into three groups of 50 patients each. All patients uniformly received oral alprazolam $0.25 \mathrm{mg}$ the night before and morning of surgery. An anaesthesiologist not involved in the study prepared and administered the pretreatment drugs. Once the patient reached the operating room, baseline recordings of vital parameters were made. Group N received $2 \mathrm{~mL}$ of $0.9 \%$ saline, Group L received 2\% lignocaine ( $40 \mathrm{mg}$ ) and Group T received thiopental $0.5 \mathrm{mg} / \mathrm{kg}$. All study drugs were made into $2 \mathrm{~mL}$ with normal saline and were administered over 5 seconds in a dedicated IV line (18 $\mathrm{g}$ ) in a vein on the dorsum of non-dependent hand while the venous drainage was occluded manually at the middle of forearm just before the administration of study drug and was maintained for one minute. Another cannula was placed on the dorsum of other hand for the infusion of IV fluids. Patients then received one fourth of the total calculated dose of propofol over 5 seconds and 15 seconds later the patient was assessed for pain during injection of propofol. The induction dose of propofol was 2.5 $\mathrm{mg} / \mathrm{kg}$. The remaining dose of propofol was administered after assessment of pain. All study drugs were kept at room temperature and used within $30 \mathrm{~min}$. of preparation. Tracheal intubation was facilitated with vecuronium and anaesthesia was maintained with isoflurane and fentanyl.

During propofol injection, vocal response, facial grimacing, arm withdrawal and tears suggesting severe pain were continuously observed. Pain was graded using four point scale as $0=$ no pain, $1=$ mild pain (pain reported only in response to questioning without any behavioural sign), $2=$ moderate pain (pain accompanied by a behavioural sign or pain reported spontaneously without questioning), $3=$ severe pain (vocal response, facial grimacing, arm withdrawal and tears).

Within 24 hours after operation, the injection site was checked for pain, oedema, and wheal and flare response by anaesthesiologist who was unaware that which drug was administered. All measured values are presented as mean + standard deviation and numbers (\%). The results were analysed statistically using unpaired student t-test and chisquare test. Results were considered statistically significant when $\mathrm{p}$ value of $<0.05$ was obtained. Statistical packages for social sciences (SPSS; Windows ver. 16.0) were used for statistical analysis.

\section{RESULTS}

All the patients included in the study were females scheduled for short gynaecological procedures. The demographic data of the study has been depicted in table 1 . All three study groups had comparable age, weight and belonged to ASA I or II physical status. The overall incidence of pain and its severity associated with propofol injection in all three groups is shown in table 2 .

\begin{tabular}{|c|c|c|c|}
\hline $\begin{array}{c}\text { Demographic } \\
\text { Variable }\end{array}$ & $\begin{array}{c}\text { Group N } \\
(\mathbf{n = 5 0 )} \\
\text { Mean } \pm \text { SD }\end{array}$ & $\begin{array}{c}\text { Group L } \\
\mathbf{( n = 5 0 )} \\
\text { Mean } \pm \text { SD }\end{array}$ & $\begin{array}{c}\text { Group T } \\
\mathbf{( n = 5 0 )} \\
\text { Mean } \pm \text { SD }\end{array}$ \\
\hline $\begin{array}{c}\text { Age } \\
\text { (years) }\end{array}$ & $28.54 \pm 5.50$ & $28.38 \pm 3.54$ & $29.40 \pm 4.73$ \\
\hline $\begin{array}{c}\text { Weight } \\
\text { (Kg) }\end{array}$ & $55.14 \pm 5.34$ & $53.66 \pm 6.59$ & $54.20 \pm 6.13$ \\
\hline $\begin{array}{c}\text { ASA physical } \\
\text { status } \\
\text { (I/II) }\end{array}$ & $39 / 11$ & $40 / 10$ & $42 / 8$ \\
\hline $\begin{array}{c}\text { Duration of } \\
\text { surgery } \\
\text { (min.) }\end{array}$ & $30.46 \pm 5.65$ & $33.36 \pm 5.70$ & $31.12 \pm 4.22$ \\
\hline \multicolumn{3}{|c|}{ Table 1. Demographic Data } \\
\hline \multicolumn{4}{|l}{}
\end{tabular}

\begin{tabular}{|c|c|c|c|c|}
\hline $\begin{array}{c}\text { Pain } \\
\text { Assessment }\end{array}$ & $\begin{array}{c}\text { Group N } \\
(\mathbf{n = 5 0 )}\end{array}$ & $\begin{array}{c}\text { Group L } \\
(\mathbf{n = 5 0 )}\end{array}$ & $\begin{array}{c}\text { Group T } \\
(\mathbf{n = 5 0 )}\end{array}$ & P value \\
\hline No pain & $14(28 \%)$ & $40(80 \%)^{*}$ & $38(76 \%)^{*}$ & $<0.001^{*}$ \\
\hline Pain & $36(72 \%)$ & $10(20 \%)^{*}$ & $12(24 \%)^{*}$ & $<0.001^{*}$ \\
\hline 1 (Mild Pain) & $6(12 \%)$ & $7(14 \%)$ & $8(16 \%)$ & 0.101 \\
\hline $\begin{array}{c}\text { 2 (Moderate } \\
\text { Pain) }\end{array}$ & $14(28 \%)$ & $2(4 \%)^{*}$ & $3(6 \%)^{*}$ & $0.017^{*}$ \\
\hline 3 (Severe Pain) & $16(32 \%)$ & $1(2 \%)^{*}$ & $1(2 \%)^{*}$ & $0.001^{*}$ \\
\hline \multicolumn{5}{|c|}{ Table 2. Incidence and Severity of Pain following } \\
Propofol Injection \\
\hline
\end{tabular}

${ }^{*} \mathrm{P}<0.05$ compared with group $\mathrm{N}$.

The incidence and severity of pain associated with propofol injection in saline group was $72 \%(36 / 50)$ as compared to $20 \%(10 / 50)$ in lidocaine group and $24 \%$ $(12 / 50)$ in thiopentone group. Pretreatment with thiopental was as effective as lidocaine to attenuate propofol injection pain when compared to saline group $(\mathrm{P}<0.05)$.

One patient each in group $\mathrm{L}$ and $\mathrm{T}$ ( $2 \%$ each) had severe pain. Two patients $(4 \%)$ in group $L$ had moderate pain as compared to three patients $(6 \%)$ in group T. The difference in pain was statistically not significant with each other, but when compared to Group N (28 and 32\% respectively) it was statistically significant. No complications such as pain, oedema or flare response were observed at the injection site within the first 24 hours after the surgery.

\section{DISCUSSION}

Over the years, much research has taken place and many analgesic interventions have been used for attenuating the pain associated with propofol injection. This study aims at minimizing propofol injection pain as an important clinical goal because it may influence the patient's perception of quality and acceptability of anaesthesia. The painless anaesthesia carries a significant effect on psychological outcome of the patient.

Double blind randomised study was conducted on 150 adult ASA physical status I/II patients undergoing short gynaecological procedures to ascertain the efficacy of pretreatment with thiopental $0.5 \mathrm{mg} / \mathrm{kg}$ and lidocaine $40 \mathrm{mg}$ after manual venous occlusion for prevention of propofol injection pain. Duration of venous occlusion and the dose of lidocaine was based on meta-analysis which concluded that the optimal method for prevention of propofol associated pain is to give IV lidocaine $0.5 \mathrm{mg} / \mathrm{kg}$ while a tourniquet is applied to the forearm for a period of 30-120 seconds before injection of propofol. 
Propofol, by an indirect action on endothelium activates the kallikrein-kinin system and releases bradykinin, thereby producing venous dilatation and hyperpermeability which increases the contact between aqueous phase of propofol and free nerve endings resulting in pain on injection.(10) Propofol when drawn up in a disposable syringe may lead to formation of irritants and hence propofol pain.(11) It has been confirmed that propofol strips the silicon lubricants from inside the barrel of plastic syringes. A reduction in propofol pain by cooling it to $4^{0} \mathrm{C}$ and diluting the propofol may slow or prevent this reaction between propofol and plastic.

The physical properties of thiopental such as its alkalinity and lipid solubility may affect the concentration of free aqueous propofol which is responsible for propofol pain. Thiopental may also exert its effect by preventing release of bradykinin and hence propofol pain.(11) Even though thiopentone has anti-analgesic properties, it has been demonstrated that in sub hypnotic doses, the combination of thiopentone and propofol produces analgesia to experimentally induced pain. ${ }^{(12)}$

Lee et al(13) reported that pretreatment with $100 \mathrm{mg}$ thiopental attenuated propofol pain when compared with lidocaine $20 \mathrm{mg}$. Nevertheless, the sedative effect of such a large dose of thiopental on perception of pain by visual analogue scale cannot be eliminated. Haugen et al(14) compared the efficacy of thiopental $50 \mathrm{mg}$. (approx. 0.8 $\mathrm{mg} / \mathrm{kg}$ ) pretreatment with lidocaine $40 \mathrm{mg}$ and observed that thiopental only reduced the severity of propofol pain whereas lidocaine reduced both the incidence and severity of pain. In our study we administered comparatively smaller dose of thiopental $(0.5 \mathrm{mg} / \mathrm{kg})$ and observed effective attenuation of propofol pain without alteration in pain perception. Anil Aggrawal et al(15) concluded that the pretreatment with lidocaine $40 \mathrm{mg}$, thiopental $0.25 \mathrm{mg} / \mathrm{kg}$ and $0.5 \mathrm{mg} / \mathrm{kg}$ after manual venous occlusion attenuates propofol pain. However, pretreatment with $0.5 \mathrm{mg} / \mathrm{kg}$ thiopental; was the most effective of all.

Our study had few limitations. Occlusion at mid forearm was done manually, which will vary from person to person, this could have been overcome by using tourniquet with constant pressure. Also, drug could have been injected using syringe pump instead of injecting manually.

\section{CONCLUSION}

Pretreatment with both lidocaine $40 \mathrm{mg}$ and thiopental $0.5 \mathrm{mg} / \mathrm{kg}$ can be used effectively in clinical practice to alleviate pain associated with propofol injection. Though lidocaine has widespread application, the study proves that thiopental pretreatment in dose range of $0.5 \mathrm{mg} / \mathrm{kg}$ along with manual venous occlusion for one minute is equally a better alternative to lidocaine with similar advantages. This simple readily available technique eliminated the unpleasant side effect of pain, allowed more tolerable induction of anaesthesia and increased patient acceptance of propofol.

\section{REFERENCES}

[1] Smith I, White PF, Nathanson M, et al. Propofol: an update on its clinical use. Anaesthesiology 1994;81(4):1005-43.

[2] Nathanson MH, Gajraj NM, Russell JA. Prevention of pain on injection of propofol, a comparison of lidocaine with alfentanyl. Anaesthesia Analgesia 1996;82(3):469-71.

[3] King SY, Davis FM, Wells JE, et al. Lidocaine for the prevention of pain due to injection of propofol. Anesth Analg 1992;74(2):246-9.

[4] Picard P, Tramèr MR. Prevention of pain on injection with propofol: a quantitative systematic review. Anesth Analg 2000;90(4):963-9.

[5] Stokes DN, Robson N, Hutton P. Effect of diluting propofol on the incidence of pain on injection and venous sequelae. Br J Anaesth 1989;62(2):202-3.

[6] Klement W, Arndt JO. Pain on injection of propofol: effects of concentration and diluent. $\mathrm{Br} \mathrm{J}$ Anaesth 1991;67(3):281-4.

[7] Ambesh SP, Dubey PK, Sinha PK. Ondansetron pretreatment to alleviate pain on propofol injection: a randomized, controlled, double blinded study. Anesth Analg 1999;89(1):197-9.

[8] Ganta R, Fee JPH. Pain on injection of propofol: comparison of lignocaine with metoclopramide. $\mathrm{Br} \mathrm{J}$ Anaesth 1992;69:316-7.

[9] Fletcher JE, Seavell CR, Bowen DJ. Pretreatment with alfentanil reduces pain caused by propofol. Br J Anaesth 1994;72(3):342-4.

[10] Coderree TJ, Katz J, Vaccarino AL, et al. Contribution of central neuroplasticity to pathological pain: review of clinical and experimental evidence. Pain 1993;52(3):259-85.

[11] Mecklem DW. Propofol injection pain: comparing the addition of lignocaine or metoclopramide. Anaesthesia Intensive Care 1994;22(5):568-70.

[12] Aanker-Moller E, Spangsberg N, Arendt-Nielsen L, et al. Subhypnotic dose of thiopentone and propofol cause analgesia to experimentally induced acute pain. $\mathrm{Br} \mathrm{J}$ Anaesth 1991;66(2):185-8.

[13] Lee TW, Lowenthal AE, Strachan JA, et al. Pain during injection of propofol: the effect of prior administration of thiopentone. Anaesthesia 1994;49(9):817-8.

[14] Haugen RD, Vaghadia H, Waters T, et al. Thiopentone pretreatment for propofol injection pain in ambulatory patients. Can J Anaesth 1995;42(12):1108-12.

[15] Anil A, Mohammad FA, Devendra G, et al. Pretreatment with thiopental for prevention of pain associated with propofol injection. Anesth Analg 2004;98(3):683-6. 